\title{
A INTERNACIONALIZAÇÃO DA INDÚSTRIA CALÇADISTA FRANCANA
}

\section{THE INTERNATIONALIZATION OF THE FOOTWEAR INDUSTRY FROM FRANCA CITY}

\author{
ALFREDO JOSÉ MACHADO NETO \\ Doutor em Administração pela Faculdade de Administração, Economia e Contabilidade \\ da Universidade de São Paulo (USP). \\ Vice-reitor do Centro Universitário de Franca (Uni-FACEF). \\ Rua Jonas Deocleciano Ribeiro, 919, Champagnat - Franca - SP - CEP 14400-230 \\ E-mail: alfredomachado@netsite.com.br
}

\section{FERNANDO CARVALHO DE ALMEIDA}

Doutor em Administração pela Universidade Pierre-Mendès-France. Professor da Faculdade de Administração, Economia e Contabilidade da Universidade de São Paulo (USP). Avenida Professor Luciano Gualberto, 908, sala G122, Butantã - São Paulo - SP - CEP 05508-900 E-mail: fcalmeida@usp.br 


\section{RESUMO}

Este estudo tem por objetivo investigar, à luz das teorias de internacionalização de empresas, as formas de inserção no mercado externo das indústrias de calçados da cidade de Franca, no Estado de São Paulo, e o estágio atual dessas empresas no processo de internacionalização de suas atividades. Foram enviados questionários às 208 empresas que compõem o universo das pequenas, médias e grandes indústrias de calçados da cidade, com um retorno de 70\%. Os resultados apurados permitem afirmar que elas seguem uma estratégia gradual de inserção no mercado internacional, em consonância com a literatura sobre o processo de internacionalização. A maioria delas se encontra, ainda, nos estágios iniciais desse processo. As principais causas para o lento desenvolvimento dessas empresas no mercado internacional são a utilização de intermediários na comercialização, a não-utilização de marcas próprias e a falta de desenvolvimento de canais próprios de distribuição no exterior.

\section{PALAVRAS-CHAVE}

Internacionalização; Indústria de calçados; Canais de distribuição; Exportação; Comércio internacional.

\section{ABSTRACT}

This study aim to investigate, based on the internationalization of companies' theories, the ways of integration into the industries of shoes' foreign market from the city of Franca, São Paulo, and the current situation of these companies in the process of internationalization of its activities. Questionnaires were sent to two hundred and eight companies that make up the universe of small, medium and large footwear industries in the city, with a return of seventy percent. The results show that they follow a strategy of gradual integration into the international market, in line with the literature on the process of internationalization. Most of them are still in the early stages of this process. The main causes for the slow 
development of these businesses in the international market are the use of intermediaries in the marketing, lack of own brands and the lack of development of their own channels of distribution abroad.

\section{KEYWORDS}

Internationalization; Footwear industry; Distribution channels; Export; International trade.

\section{INTRODUÇÃO}

As questões relativas ao comércio internacional têm assumido uma relevância cada vez maior no debate econômico nacional, em razão, principalmente, da necessidade das empresas de aumentarem sua competitividade em um mercado cada vez mais globalizado. Dentro desse contexto, pode-se identificar a importância de estudar setores da economia brasileira que tenham possibilidade de elevar o volume das vendas externas, em especial aqueles setores da indústria que tenham por característica a utilização de mão-de-obra intensiva, como é o caso da cadeia coureiro-calçadista. $\mathrm{O}$ incremento das exportações desse setor é relevante não apenas para melhorar os resultados das contas externas do país, como também para reduzir as taxas de desemprego.

Este trabalho pretende identificar as formas adotadas pela indústria de calçados da cidade de Franca, no Estado de São Paulo, para sua inserção no mercado externo, e mesmo a internacionalização de suas atividades produtivas. Além desse objetivo geral, procurou-se analisar o atual estágio de desenvolvimento dessas empresas em seu processo de internacionalização e verificar o grau de concentração das vendas externas, tanto em relação a países como a compradores internacionais.

Inicialmente, delineia-se o contexto da indústria calçadista no Brasil, mostrando a localização espacial dos principais produtores. O próximo item apresenta um breve histórico da atuação da indústria brasileira de calçados no mercado internacional. Em seguida, o foco volta-se para o objeto deste estudo: a indústria de calçados da cidade de Franca, que é especializada na produção de calçados masculinos de couro, vendidos para todos os estados brasileiros, que tem importante participação no mercado externo e se constitui no principal pólo calçadista do Estado de São Paulo. O marco teórico, apresentado a seguir, contempla as principais vertentes das teorias sobre a internacionalização de empresas. Por fim, são apresentados a metodologia utilizada, os resultados da pesquisa empírica, assim como as conclusões e as recomendações. 


\section{O CONTEXTO DA INDÚSTRIA CALÇADISTA NIO BRASIL}

Um estudo do Sindicato da Indústria de Calçados de Franca (SINDIFRANCA, 2002) mostra que, historicamente, a produção de calçados no Brasil concentrava-se, principalmente, em dois pólos. O primeiro deles situava-se no Vale dos Sinos (RS), especializado em calçados femininos, e era responsável por $40 \%$ da produção nacional, $75 \%$ das exportações totais e quase $50 \%$ dos empregos do setor. O segundo, em Franca (SP), com cerca de 760 empresas (MACHADO NETO, 2006), concentrava sua produção em calçados de couro masculino, respondendo por $6 \%$ da produção nacional e $3 \%$ das exportações do Brasil.

Ainda se destacavam Birigüi (SP), com r8o empresas de calçados infantis, sendo $2 \%$ da produção nacional e $2,5 \%$ das exportações totais, e Jaú (SP), com I50 empresas de calçados femininos, respondendo por $2 \%$ da produção nacional e menos de $0,5 \%$ das exportações totais. As empresas localizadas nessas três cidades do Estado de São Paulo - Franca, Birigüi e Jaú - absorviam cerca de ı8\% da mão-de-obra empregada do setor.

O estudo citado enfatiza também outros dois pólos tradicionais da indústria calçadista: Santa Catarina e Minas Gerais. A indústria de calçados de Santa Catarina, especializada em calçados femininos, concentrava-se na cidade de São João Batista, onde se encontravam I20 empresas que fabricavam cerca de $\mathrm{I} \%$ da produção nacional. O setor calçadista de Minas Gerais era composto por cerca de I.500 empresas que se concentravam, principalmente, em Belo Horizonte e eram especializadas em calçados femininos e também 730 empresas, em Nova Serrana, que produziam tênis e chinelos em material sintético e eram responsáveis por cerca de I०\% da produção nacional.

A partir da década de I990, com a migração de grandes empresas das regiões Sul e Sudeste, surgiu um novo pólo calçadista no Nordeste. A formação dos novos pólos calçadistas no Nordeste decorreu, basicamente, de dois fatores: os insuperáveis subsídios concedidos pelos governos nordestinos, em especial do Ceará, da Paraíba e da Bahia; e os salários pagos aos trabalhadores desses estados que eram, em média, a metade dos praticados na cidade de Franca e do Vale dos Sinos (HENRIQUES, I999).

A cadeia coureiro-calçadista possuía uma relevante importância para a economia brasileira, não apenas pelo volume de exportações, que somaram 2I2 milhões de pares e um ingresso de divisas da ordem de US\$ I.809 milhões, no ano de 2004 , como pela geração de empregos, em torno de 3I3 mil postos de trabalho, no mesmo ano, considerados apenas os empregos diretos nas 8,4 mil indústrias de calçados que o compunham (ABICALÇADOS, 2006). 
Segundo a mesma fonte, a grande variedade de fornecedores de matériaprima e componentes (I,5 mil indústrias), de máquinas e equipamentos (cerca de Ioo indústrias), aliada à tecnologia de produtos e inovações, fez do setor coureiro-calçadista brasileiro um dos mais importantes do mundo. Além disso, em 2005 mais de 400 empresas especializadas no curtimento e acabamento do couro processaram mais de 30 milhões de peles.

Em 2004, o setor calçadista brasileiro produziu cerca de 725 milhões de pares de calçados. Embora esse período tenha sido um dos mais expressivos para a indústria de calçados nacional, com recuperação dos níveis de produção anteriores ao Plano Real, e tenha alcançado bom desempenho nas exportações, o setor passou a enfrentar, desde o final desse ano, uma grave crise em decorrência do baixo valor do dólar, que trouxe como conseqüências a perda de competitividade dos produtos do setor no mercado externo e a redução de suas exportações (ABICALÇADOS, 2006).

\section{A ATUAÇÃO NO MERCADO EXTERNO}

Na década de I980, tendo em vista a necessidade de divisas (dólares), o governo federal brasileiro implantou uma política de incentivo às exportações (REIS, I994), cujo objetivo principal era a obtenção de saldos positivos na balança comercial, com a finalidade de atender aos encargos financeiros da dívida externa. Para tanto, o governo buscou promover as exportações e conter as importações. Foram vários os incentivos implementados pela política econômica governamental, com a finalidade de fomentar as exportações na década de i980 (isenções de impostos, subsídios, benefícios fiscais a programas de exportação), além de uma política cambial caracterizada por constantes minidesvalorizações.

Aproveitando tais benefícios, a indústria calçadista expandiu suas exportações de forma significativa. Passou de 22 milhões de pares e um ingresso de divisas da ordem de US\$ 93 milhões, em I973, para 93 milhões de pares e US\$ 682 milhões de divisas em I983, atingindo seu ponto mais alto em I993, com a exportação de 20I milhões de pares e o ingresso de US\$ I.846 milhões em divisas (ABICALÇADOS, 2006).

Com a implantação do Plano Real em I994, a indústria calçadista brasileira apresentou uma queda expressiva em sua atuação no mercado externo, em decorrência de uma valorização irreal de nossa moeda em relação ao dólar, que retirou a competitividade dos produtos brasileiros no exterior.

Em 2000, dois anos após o fim da paridade cambial, o setor deu início ao processo de recuperação das vendas externas; mas, somente em 2004 (mais de dez anos depois), conseguiu suplantar a quantidade de pares exportada em 
I993, porém sem alcançar o faturamento obtido em 2004, que só foi superado em 2005.

No ano de 2004, com uma produção de 755 milhões de pares, o Brasil se colocou como o terceiro maior produtor de calçados do mundo; o quinto maior exportador, com um volume exportado de $2 \mathrm{I} 2$ milhões de pares; e o quinto maior consumidor de calçados do planeta, com um consumo anual de $552 \mathrm{mi}$ lhões de pares. Em 2005, os números da indústria calçadista foram um pouco inferiores: 725 milhões de pares produzidos, I89 milhões de pares exportados e 552 milhões de pares consumidos.

Uma característica importante a se destacar na indústria calçadista é o grande volume das exportações concentrado em um número reduzido de empresas. Em 2004, do total de US\$ I, 9 bilhão de faturamento obtido pelo setor com as exportações, cerca de US\$ I,2 bilhão $(65,9 \%)$ ficou com apenas 46 empresas, que representavam 3,7\% do total das exportadoras. As outras I.2I8 empresas exportadoras do setor faturaram US\$ 699 milhões no mercado externo, ou cerca de 34,I\% do valor total obtido com exportações de calçados naquele ano (MDIC/ SECEX, apud ABICALÇADOS, 2006).

No Brasil, a concentração das exportações realizadas por um pequeno número de empresas não ocorre apenas no setor calçadista. Seragini (apud NEVES et al., 200I) mostra que, de um total de 2 milhões de estabelecimentos industriais, apenas I5 mil empresas brasileiras exportam. Além disso, 60\% do total das exportações é realizado por menos de mil empresas, sendo que $40 \%$ do valor exportado corresponde a transações entre empresas (business-to-business).

Segundo Campanhol e Smith (2002, p. 335), as dificuldades encontradas pelas empresas brasileiras - especialmente as micro e pequenas indústrias de calçados de Franca (SP) -, para ingressar no mercado internacional, estão concentradas principalmente "na comercialização não centrada na marca, qualidade ou estilo, ou seja, o calçado francano não tem identidade no exterior".

Uma pesquisa realizada pelo Sebrae (2004), com 87 indústrias calçadistas da cidade de Franca, mostra que 70\% das exportações de calçados são realizadas por intermédio de agentes de exportação e com marcas de terceiros, normalmente das grandes distribuidoras internacionais. Ao realizarem suas vendas para essas distribuidoras internacionais, as empresas do setor não desenvolvem marcas próprias no exterior nem canais próprios de distribuição. São os agentes que determinam os modelos a serem fabricados, exigem a colocação de suas marcas nos produtos e estipulam os preços a serem pagos.

Outro aspecto preocupante nas exportações da indústria calçadista brasileira é a excessiva dependência do mercado norte-americano. Do total exportado em 2004, ou seja, US\$ I,8I bilhão (56,6\%), US\$ I,02 bilhão - correspondente a cerca de 97,6 milhões de pares - foi vendido para os Estados Unidos. O segundo 
mercado da indústria brasileira de calçados é o Reino Unido, que naquele ano importou do Brasil 9,5 milhões de pares de calçados, por US\$ 136 milhões de dólares.

Nas exportações brasileiras, predominam os calçados com cabedal de couro, que são produtos com maior valor agregado, destinados a um público de renda média (REIS, I994) - o que se diferencia, por exemplo, dos países asiáticos, principalmente China, Coréia do Sul, Hong Kong e Taiwan, que se especializaram na produção de calçados esportivos de material sintético (GARCIA, 200I; REIS, I994).

Em 2004, o Brasil exportou cerca de I23 milhões de pares de calçados com cabedal de couro, que proporcionaram um ingresso de divisas da ordem de US\$ I, 4 bilhão de dólares, correspondente a cerca de $80,3 \%$ do valor das exportações do país naquele ano; esse tipo de calçado obteve um preço médio de US\$ II,8I no mercado externo. O segundo produto mais exportado - o calçado de plástico montado - apresentou um volume de vendas da ordem de $6_{3} \mathrm{mi}$ lhões de pares, com um faturamento de cerca de US\$240 milhões, a um preço médio de US\$ 3,8I por par de calçado exportado (ABICALÇADOS, 2006).

\section{A INDÚstria CALÇAdista FrAncANA}

A indústria de calçados da cidade de Franca (SP) - foco deste estudo - é especializada na produção de calçados masculinos de couro, vendidos para todos os estados brasileiros, tem importante participação no mercado externo e se constitui no principal pólo calçadista do Estado de São Paulo (CONSTANZI, I999).

Estimativas do Sindifranca (2006) mostram que o setor que empregava, no final de 2004, cerca de 23 mil funcionários, registrados em suas 760 indústrias, produziu, naquele ano, 35,4 milhões de pares, sendo 25,3 milhões destinados ao mercado interno e Io,I milhões vendidos no mercado externo, correspondentes a $5 \%$ das exportações nacionais. No ano de 2005 , o setor apresentou uma queda em todos estes números: I8 mil postos de trabalho (-2I,7\%); 27,9 milhões de pares produzidos (-21,2\%); I9,6 milhões de pares vendidos no mercado interno $(-22,5 \%)$; e 8,3 milhões de pares exportados $(-17,8 \%)$, correspondendo a $4,5 \%$ das exportações nacionais (SINDIFRANCA, 2006).

Mesmo com a recuperação parcial das vendas externas do setor, ocorrida nos últimos anos, essa queda de rendimento, de 2004 para 2005, pode ser reflexo de algumas deficiências históricas do setor, como a concentração das exportações em um número relativamente pequeno de empresas, a dependência dos agentes de exportação, o pequeno volume de vendas com marca própria, a ausência de canais de distribuição próprios e a preponderância nas vendas para 
o mercado norte-americano, além da fragilidade do setor diante das variações das taxas de câmbio.

Finalizado o delineamento do setor calçadista brasileiro, a próxima parte do artigo apresenta os conceitos relacionados às teorias sobre o processo de internacionalização das empresas e sua aplicação à indústria calçadista.

\section{AS TEORIAS SOBRE O PROCESSO DE INTERNACIONALIZAÇÃO DA EMPRESA}

Para Dal-Soto (2006, p. 2), “a internacionalização pode ser definida como um processo crescente e continuado de envolvimento das operações de uma empresa com outras de países fora de sua base de origem". Boa parte dos modelos que tratam das estratégias de entrada no mercado externo defende a idéia de que a internacionalização da empresa ocorre por meio de uma série de etapas, cujo número e cuja natureza diferem de acordo com o autor.

Esse enfoque da internacionalização como um processo seqüencial abrange diversos modelos que, embora apresentem concepções diferentes, partem de uma premissa básica comum: as empresas, no desenvolvimento de suas atividades internacionais, evoluem de forma seqüencial e consistente por meio de uma aprendizagem organizacional contínua.

\subsection{O MODELO DE JOHANSON E VAHLNE}

De acordo com Melin (1992), dentre todos os modelos que compartilham o caráter seqüencial da internacionalização, o mais citado, discutido e com maior influência no campo dos negócios é o desenvolvido pela Escola Escandinava.

A Teoria das Fases de Desenvolvimento estabelece que a empresa passa por quatro diferentes estágios no processo de penetração em um mercado estrangeiro, constituindo o que os autores denominam "cadeia de estabelecimento" (JOHANSON; WIEDERSHEIM-PAUL, I975):

- Estágio I - Exportações esporádicas não regulares;

- Estágio 2 - Exportações por intermédio de representantes independentes;

- Estágio 3 - Implantação de filial comercial no país estrangeiro;

- Estágio 4-Implantação de unidade produtiva no país estrangeiro.

Esse padrão de comportamento é decorrente de um processo de decisão racional das empresas que buscam, ao mesmo tempo, reduzir o risco da atuação em mercados internacionais e preservar o status quo existente na empresa 
(DOMINGUINHOS, 200I). Assim, o montante dos recursos que a empresa irá investir no mercado-alvo depende do grau de conhecimento que ela possui desse mercado. Quanto maior o conhecimento, maior será o volume de recursos que a empresa estará propensa a investir.

O segundo corolário desse modelo está relacionado com a progressão geográfica das atividades internacionais, associada ao conceito de distância psicológica, definida como o conjunto de fatores que impedem ou dificultam os fluxos de informação entre a empresa e o mercado-alvo: diferenças lingüísticas, culturais, políticas, educacionais ou de desenvolvimento industrial.

Johanson e Vahlne (I990) admitem a possibilidade de ocorrerem exceções ao processo linear e seqüencial de ingresso no mercado externo. Segundo os autores, existem casos em que as empresas possuem recursos suficientes e, dessa forma, podem dar saltos maiores, adquirindo, por exemplo, empresas instaladas no mercado-alvo. Também, quando as condições dos mercados são estáveis e homogêneas, o conhecimento relevante das empresas pode ser obtido de outras formas que não seja a experiência, como, por exemplo, pela contratação de recursos humanos especializados. Por último, as empresas com larga experiência em mercados com condições semelhantes podem generalizá-la para um mercado específico.

Em um artigo mais recente, Johanson e Vahlne (2006) dão ênfase ao papel das networks não apenas para a redução das incertezas, mas também para o desenvolvimento de oportunidades de negócios no exterior. Ressaltam que o modelo inicial desenvolvido por eles não se constitui em uma simples cadeia de estabelecimento, que se desenvolveria da exportação inicial até a instalação de unidades produtivas em outros países, mas trata da relação entre a aprendizagem organizacional e o aumento do comprometimento no mercado externo. $\mathrm{O}$ aprendizado e o comprometimento, embora importantes para a redução da incerteza, possibilitam ainda a descoberta ou o desenvolvimento de oportunidades de negócios no mercado internacional (JOHANSON; VAHLNE, 2006; GONÇALVES, 2008).

\subsection{O MODELO DE INOVAÇÃO}

Paralelamente ao modelo desenvolvido pela Escola Escandinava, e seguindo também o enfoque seqüencial, surge outra corrente de autores: Bilkey e Tesar (I977), Cavusgil (I988a), Reid (I98I), Czinkota e Johnston (I985) - cujos trabalhos dão origem ao chamado Modelo I, por enfocarem o processo de internacionalização da empresa sob a perspectiva de uma inovação (ANDERSEN, 1993).

Tal processo está integrado por um conjunto de modelos que têm em comum, por um lado, a defesa do caráter seqüencial do referido processo e, por 
outro, a utilização de determinados níveis de comprometimento com a atividade exportadora, por parte da empresa, como variável definidora das distintas etapas de expansão internacional desta.

\subsection{AS NETWORKS NO PROCESSO DE INTERNACIONALIZAÇÃO}

Para Raboch e Amal (2008), a Teoria das Redes de Relacionamentos (networks) pode ser considerada uma evolução natural do modelo da Escola de Uppsala, que passou a ser conhecida como Escola Nórdica de Negócios Internacionais. Seus seguidores "têm desempenhado um papel central no desenvolvimento da perspectiva das networks industriais, focalizando os relacionamentos existentes entre firmas e mercados industriais" (HEMAIS; HILAL, 2002, p. 30). Segundo Barretto (I998, p. 52),

[...] uma network é formada por relações comerciais duradouras desenvolvidas e mantidas através de interações entre diferentes empresas atuantes em mercados industriais - por exemplo clientes, clientes de clientes, fornecedores, distribuidores, agentes, concorrentes - que constroem, assim, uma base de conhecimento e confiança recíprocos

Para Souza, Dreher e Amal (2007, p. I08), os participantes de uma rede são mutuamente interdependentes e a coordenação de suas atividades "ocorre através do próprio processo de entrelaçamento das transações desenvolvidas pelas empresas, reduzindo assim uma parte significativa dos custos de transação". Desse modo, as ações e estratégias dos integrantes da rede não são orientadas para a realização de benefícios imediatos, mas para preservar a eficiência da rede como um todo, e também a da própria empresa a longo prazo (SOUZA; DREHER; AMAL, 2007).

Johanson e Vahlne (2003) ressaltam, no entanto, que, na ótica do modelo de networks, as dificuldades para a inserção em novos mercados estão relacionadas mais com os problemas gerenciais associados ao estabelecimento e desenvolvimento de relações com os clientes ou os fornecedores do que com a existência de eventuais barreiras à internacionalização. De qualquer modo, o processo de internacionalização continua a ser resultado da interação entre um aprendizado organizacional gradativo, baseado na experiência e no comprometimento com os novos mercados, variáveis que passam a depender, também, da capacidade e do potencial dos parceiros existentes na rede (JOHANSON E VAHLNE, 2003). 


\subsection{AS CRÍTICAS AO MODELO SOBRE O COMPORTAMENTO EXPORTADOR}

A Teoria Comportamentalista de Inserção no Mercado Internacional, mesmo tendo sido respaldada por diversas pesquisas, é objeto de críticas por parte de alguns estudiosos do processo de internacionalização.

Uma das principais críticas ao modelo é sua visão determinista em não reconhecer que a firma pode permanecer em um determinado estágio e não evoluir, bem como adotar uma estratégia diferente quanto aos modos de entrada e expansão no mercado internacional (ANDERSEN, I993). Também são feitas críticas à consistência teórica desses modelos, por considerá-los conceitual e metodologicamente insuficientes, incapazes de explicar por que o processo ocorre (ou não) e de predizer a passagem de um estágio de internacionalização para o seguinte (ANDERSEN, I993).

\subsection{AS TEORIAS DOS CUSTOS DE TRANSAÇÃO E INTERNALIZAÇÃO}

Uma outra abordagem sobre o processo de internacionalização de empresas é proporcionada por um conjunto de teorias que procura explicar o comportamento das empresas com base no conceito de "custos de transação". Os conceitos iniciais dessa teoria foram expostos por Williamson (apud BARRETO, I998) e partem do princípio de que as empresas poderiam se utilizar, basicamente, de duas formas para organizar suas atividades: mercados, pela contratação externa de atividades; e hierarquias, pela utilização de sua própria estrutura para conduzir essas atividades. A empresa faria uma opção pela alternativa que apresentasse um custo de transação mais favorável, considerando-se os aspectos relativos às variáveis ambientais (incerteza e complexidade) e comportamentais (racionalidade limitada e oportunismo). Tal abordagem se apresenta sob duas formas principais: a Teoria da Internalização e o chamado Paradigma Eclético de Produção (BARRETTO, 2002).

Segundo o mesmo autor, a Teoria da Internalização pode ser considerada como a Teoria dos Custos de Transação aplicada aos negócios internacionais. Para os teóricos desse modelo, é possível considerar a exportação apenas como o ponto de partida para o investimento direto no exterior, que ocorreria quando os benefícios da internalização superassem seus custos.

Rugman (apud BARRETO, I998) propõe os seguintes estágios para o processo de internalização: primeiro, exportação; segundo, investimento direto; e terceiro, licenciamento. O Paradigma Eclético de Produção foi desenvolvido por Dunning (I988) e se propõe a explicar a amplitude, a forma e o padrão da produção 
internacional, com base em imperfeições do mercado que originariam três grupos de vantagens: as vantagens específicas de propriedade (Ownership); as vantagens de localização (Location); e as vantagens da internalização (Internalization).

As vantagens de propriedade se referem tanto à posse de direitos de propriedade ou ativos intangíveis (patentes, marcas, capacidades tecnológica e de organização, estrutura de recursos e conhecimento), como às vantagens oriundas da administração de uma rede de ativos localizados em diferentes países, que resultam da própria característica multinacional da empresa (ORTEGA, I999; IGLÉSIAS; VEIGA, 200I).

As vantagens de localização estão relacionadas à disponibilidade de recursos naturais e humanos (custo e qualidade dos recursos); ao conhecimento tecnológico; à infra-estrutura; ao tamanho do mercado; à estabilidade política e econômica; ao regime cambial; e à política econômica governamental - que definiriam onde se daria a produção. Elas tendem a refletir não apenas "recursos do tipo ricardiano como a distribuição espacial da dotação dos fatores, como também ativos derivados do ambiente cultural, legal, político e institucional” (ORTEGA, I999, p. 32).

As vantagens da internalização surgem pela existência de deficiências transacionais do mercado, que levam as empresas a diversificar e a realinhar a organização de suas atividades de valor, em parte para "maximizar o lucro líquido dos custos de transação menores derivados da direção comum, e em parte para assegurar-se da obtenção do máximo rendimento econômico das vantagens de propriedade que possuem" (ORTEGA, I999, p. 32).

\section{METODOLOGIA}

De acordo com Machado Neto (2006), existem 760 indústrias de calçados na cidade de Franca, no Estado de São Paulo, que se encontram assim distribuídas quanto ao porte: 552 microempresas; 130 empresas de pequeno porte; 65 empresas de porte médio; e I3 empresas de grande porte.

Para efeito deste trabalho, foram excluídas as microempresas, já que a pesquisa original - da qual este estudo foi derivado - tinha por foco analisar o comportamento da indústria na exportação, e a atuação das micro não é significativa quando se trata de comércio internacional.

O universo da pesquisa foi composto, então, pelas outras 208 indústrias de calçados da cidade de Franca: 130 de pequeno porte; 65 de porte médio; I3 de grande porte. A metodologia utilizada para o enquadramento das empresas pelo porte é aquela adotada pelo IBGE e pelo Sebrae. Esse critério de classificação das 
empresas pelo número de empregados foi utilizado por Carvalho Neto (2004), Dourado (200I), Smith (2000), e Figueiredo e Almeida (I988), em trabalhos sobre a indústria calçadista.

Optou-se por enviar o questionário por e-mail a todas as 208 empresas constantes do Cadastro da Indústria Calçadista de Franca, das quais 146 colaboraram com a pesquisa respondendo aos questionários - o que representou uma significativa taxa de retorno de mais de $70 \%$. A pesquisa foi respondida, em grande parte, pelos diretores e pelos principais executivos das empresas, que expressaram suas percepções em relação aos diversos aspectos do processo de internacionalização de suas indústrias.

\subsection{ANÁLISE MULTIVARIADA DE DADOS}

Diversos procedimentos estatísticos foram desenvolvidos com a finalidade de analisar os dados coletados.

Como forma de redução dos dados obtidos, foi utilizada a análise fatorial (HAIR et al., 2005). Por meio de uma análise de conglomerados, procurou-se testar a possibilidade estatística de se efetuar uma separação das empresas da amostra em três grupos homogêneos: não exportadoras, exportadoras eventuais e exportadoras experientes.

Em seguida, foi efetuada uma análise de regressão logística (AAKER et al., 200I; PESTANA; GAGEIRO, 2003; HAIR et al., 2005). A regressão múltipla foi utilizada neste trabalho para prever e explicar as variáveis e os fatores que mais discriminam os grupos de empresas.

\section{RESULtAdOS dA pESQUISA}

Neste subitem, são analisados os principais aspectos que envolvem o processo de internacionalização das empresas, cuja análise deve oferecer subsídios para se verificar se os modelos de internacionalização da firma, existentes na literatura, explicam adequadamente o comportamento da indústria calçadista francana em sua inserção no mercado internacional.

\subsection{A INSERÇÃO NO MERCADO EXTERNO}

As teorias sobre a internacionalização das empresas, em especial o Modelo de Uppsala (U-Model), estabelecem que a empresa passa por quatro estágios, conforme visto anteriormente: 
- primeiro, exportações esporádicas não regulares;

- segundo, exportações por intermédio de representantes independentes;

- terceiro, implantação de filial comercial no país estrangeiro;

- quarto, implantação de unidade produtiva no país estrangeiro.

Para verificar se o comportamento da indústria calçadista francana se ajustava a esse padrão evolutivo, foi solicitado às empresas que enumerassem a seqüência utilizada por elas na internacionalização de suas atividades, dentre as seguintes: vendas por consórcios de exportação; vendas por agentes de exportação; vendas autônomas (exportação direta); instalação de subsidiárias comerciais no exterior; e instalação de unidades de produção no exterior.

\section{TABELA I}

INDÚSTRIA CALÇADISTA DE FRANCA: FORMAS DE INSERÇÃO NO MERCADO EXTERNO

\begin{tabular}{lccccc}
\hline \multicolumn{1}{c}{ ETAPAS DA } & \multicolumn{5}{c}{ FORMAS DE INSERÇÃO } \\
\hline INTERNACIONALIZAÇÃOO & CONSÓRCIOS & AGENTES & AUTÔNOMAS & $\begin{array}{c}\text { SUBSIDIÁRIAS } \\
\text { COMERCIAIS }\end{array}$ & $\begin{array}{c}\text { UNIDADES DE } \\
\text { PRODUÇÃ̃O }\end{array}$ \\
\hline Não utiliza & 135 & 56 & 90 & 133 & 143 \\
\hline $1^{\text {a. }}$ etapa & 1 & 75 & 21 & 1 & 0 \\
\hline $2^{\text {a }}$ etapa & 5 & 13 & 28 & 2 & 0 \\
\hline $3^{\text {a }}$ etapa & 2 & 0 & 5 & 5 & 1 \\
\hline $4^{a}$. etapa & 1 & 0 & 0 & 3 & 0 \\
\hline Total & 144 & 144 & 144 & 144 & 144 \\
\hline
\end{tabular}

Fonte: Elaborada pelos autores.

Os resultados obtidos da Tabela I permitem inferir que o processo de inserção da indústria calçadista francana no mercado internacional pode ser explicado, em parte, pelas teorias de internacionalização. A maioria das empresas exportadoras iniciou suas atividades no exterior a partir da segunda das etapas que elas preconizaram, ou seja, a venda por intermédio de agentes de exportação.

Essa forma de colocação dos produtos no mercado internacional continua a ser utilizada até hoje por grande parte das empresas exportadoras, mesmo por 
aquelas que já possuem grande experiência de exportação. Isso significa dizer que, ao continuar a vender por intermédio de terceiros, as empresas francanas aparentemente não adquiriram o necessário conhecimento dos mercados externos que lhes permitisse avançar para as etapas posteriores, ou seja, instalação de subsidiárias e/ou unidades produtivas no exterior.

Entretanto, é importante destacar que o contato com os empresários durante a aplicação dos questionários permitiu verificar a existência de empresas que estão procurando modificar essa forma tradicional de conduta.

Uma das empresas entrevistadas, por exemplo, só comercializa seus produtos no exterior com marcas próprias, efetua suas vendas por intermédio de subsidiárias comerciais instaladas no exterior e exporta seus produtos para mais de 35 países. Contrariando o comportamento tradicional das empresas familiares, ela se prepara para abrir seu capital com a venda de ações na bolsa de valores. Em um período marcado por uma crise cambial que tem dificultado as exportações de calçados da cidade e obrigado algumas empresas a reduzirem sua produção, a indústria mencionada aumentou sua produção em cerca de $20 \%$.

Outra empresa, de médio porte, aproveitando as boas condições do mercado externo e a alta do dólar, já está produzindo na China mais da metade dos calçados que distribui no mercado interno. Outra ainda, que trabalha com peles de animais exóticos e logicamente com produtos diferenciados, de alto valor agregado e destinados a clientes de alta renda, também apresenta uma elevação de suas exportações no período considerado. Uma última, que explora o lucrativo nicho de mercado dos calçados anatômicos e voltados para o conforto dos pés, está vendendo seus produtos com a marca própria, em uma rede de lojas que também levam sua marca, no Japão.

Essas experiências mostram que a obtenção de melhores resultados na internacionalização das atividades da indústria calçadista da cidade de Franca deve passar por medidas que diminuam sua dependência em relação aos agentes de exportação e que acelerem a diversificação de mercados, em especial incrementando as vendas para países do Mercado Comum Europeu. Essas medidas passam pela produção de calçados de maior valor agregado, a fim de escapar da concorrência com os produtos chineses; pela exportação com marca própria; e pela implantação de representações comerciais em outros países - fatores que permitiriam a construção de canais próprios de distribuição no exterior.

Assim, a premissa contida nas teorias da internacionalização - de que as empresas começam a exportar tarde e fazem sua inserção no mercado internacional de forma paulatina e seqüencial - parece se confirmar na indústria calçadista francana até o presente momento, embora de forma muito lenta. 


\subsection{ETAPAS DA INTERNACIONALIZAÇÃO}

A comercialização por intermédio de agentes ainda é a forma mais utilizada pelas empresas calçadistas da cidade de Franca para a colocação de seus produtos no mercado externo. Das 8I empresas que exportaram no ano de 2005, 73 delas responderam que utilizam os agentes de exportação, sendo que, destas, 3I vendem toda a mercadoria exportada por intermédio deles. A segunda forma de comercialização mais utilizada é a exportação direta, mencionada por 49 empresas. Apenas 8 empresas responderam que têm subsidiárias comerciais no exterior e somente 6 disseram que integram consórcios de exportação.

O Gráfico I mostra que, por um lado, as vendas por intermédio destes dois últimos canais são ainda irrisórias, atingindo pouco menos de $2 \%$ das exportações e, por outro lado, as exportações por intermédio de agentes correspondem a 66\% das exportações e a exportação direta a 32\% delas.

As formas mais utilizadas pelas indústrias que compõem a amostra, para colocar seus produtos no exterior, são consideradas, nas citadas teorias da internacionalização, como as mais embrionárias etapas do processo de inserção internacional. Das 8I empresas que exportaram produtos no ano de 2005 , apenas 8 assinalaram ter avançado para a terceira etapa do processo, com a instalação de subsidiárias comerciais no exterior e uma única empresa já estabeleceu uma unidade produtiva fora do país.

\section{GRÁFICO I}

FORMAS DE COMERCIALIZAÇÃO PARA EXPORTAÇÃO DE SAPATOS (EM \% DO FATURAMENTO)

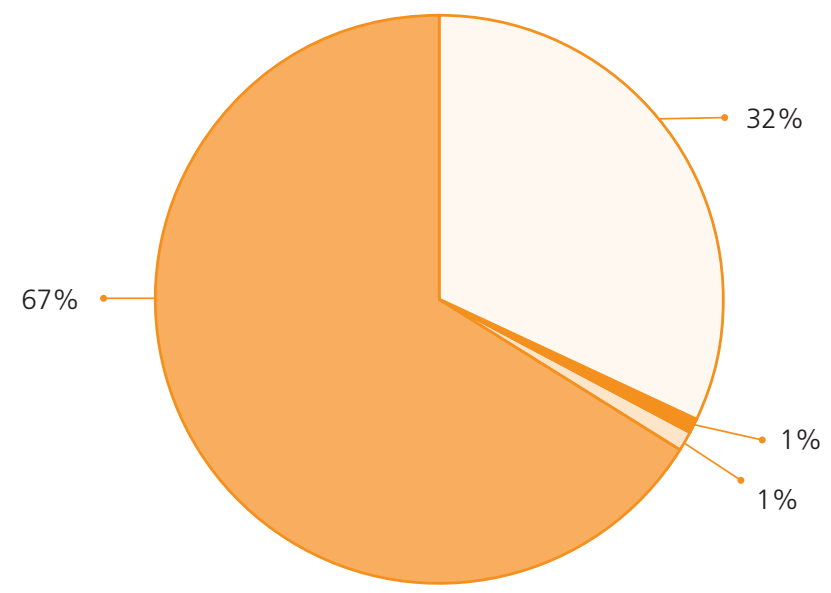

Agente

Direta

Subsidiária comercial

Consórcio 
A não-instalação de unidades fabris no exterior e a manutenção das atividades produtivas na cidade de Franca e no entorno, como já visto, talvez se devam aos salários pagos localmente, assim como aos demais custos de produção no arranjo produtivo local, que possibilitaram à indústria calçadista francana manter, pelo menos até o momento da pesquisa, a competitividade internacional. O tamanho do mercado interno, que absorve mais de $70 \%$ da produção das empresas locais, e o destino preferencial das exportações ser os Estados Unidos são outros fatores que fizeram as empresas locais não apresentarem um interesse mais forte em internacionalizar sua produção.

Atualmente, a forte presença da China no mercado norte-americano e seu ingresso no mercado nacional, no entanto, parece que fizeram esse cenário começar a se modificar, fazendo com que algumas empresas exportadoras transferissem parte de sua produção para unidades no Nordeste e para o exterior. Pelo menos uma grande empresa, aproveitando os incentivos fiscais e a mão-de-obra mais barata do Nordeste, já produz nesta região $70 \%$ dos produtos que exporta para os Estados Unidos. Outra empresa, de porte médio, aproveitando as condições favoráveis nas áreas cambial, tributária e de custos de produção, instalou uma unidade produtiva na China, onde fabrica $50 \%$ dos produtos que distribui em nosso país.

O segundo corolário do modelo de internacionalização está relacionado com a progressão geográfica das atividades internacionais, associada ao conceito de "distância psicológica", que pode ser definida como o conjunto de fatores que impedem ou dificultam os fluxos de informação entre a empresa e o mercadoalvo: diferenças lingüísticas, culturais, políticas, educacionais ou de desenvolvimento industrial.

Embora a distância psíquica possa ser normalmente correlacionada à distância geográfica, isso não corresponde, necessariamente, à realidade. Alguns países da comunidade britânica são geograficamente distantes, como, por exemplo, a Inglaterra e a Austrália, mas, por razões diferentes, eles estão próximos em termos de distância psíquica. No entanto, os Estados Unidos e Cuba estão geograficamente próximos um do outro, mas, por razões políticas, encontram-se bastante afastados quanto à distância psíquica.

Assim, em relação à distância psicológica é preciso considerar que a exportação é feita por intermédio de agentes - quase sempre, representantes de grandes empresas distribuidoras internacionais (norte-americanas em sua maioria) - e que os EUA são o maior importador mundial de calçados. Esses fatos contribuem para que as exportações da indústria francana se dirijam, predominantemente, para aquele mercado. Tal comportamento é reforçado, ainda, pelo fato de o Brasil, desde o final da Segunda Guerra Mundial ter estado, em geral, alinhado politicamente com os Estados Unidos, embora não se possa dizer que os usos, os costumes e as práticas comerciais sejam semelhantes entre os dois países. 
Não obstante, as exportações são efetuadas pelos agentes de exportação que, como representantes de grandes companhias comerciais internacionais, conhecem o mercado norte-americano, o que permite a redução de uma eventual distância psicológica entre os dois países e a colocação dos Estados Unidos como o principal mercado para os calçados da indústria francana.

\section{GRÁFICO 2}

\section{INDÚSTRIA CALÇADISTA: DESTINO DA PRODUÇÃO} PARA EXPORTAÇÃO (EM \% DO FATURAMENTO)"

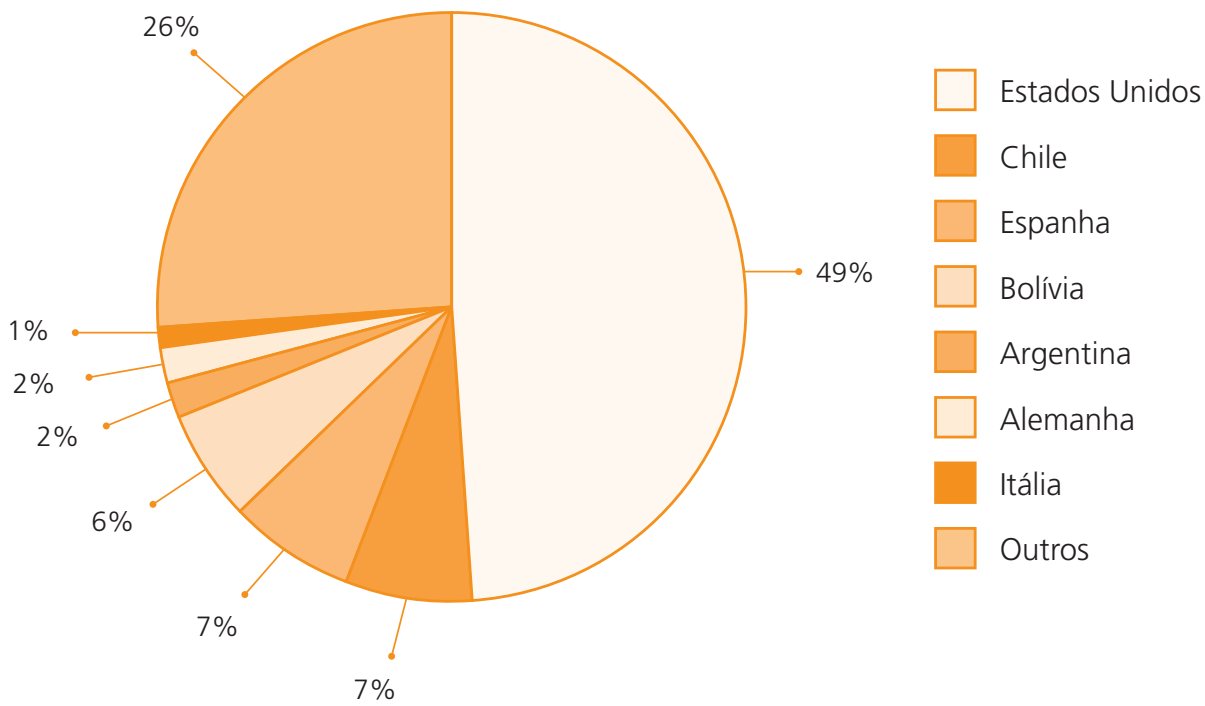

Fonte: Elaborado pelos autores.

O Gráfico 2 permite verificar que as vendas das empresas que compõem a amostra representam cerca de $50 \%$ do faturamento para o exterior direcionado ao mercado norte-americano, vindo a seguir o Chile, a Espanha e a Bolívia, com participações percentuais em torno de $6 \%$ a $7 \%$ cada um. Embora com participações ainda pequenas no faturamento das vendas externas das empresas francanas, o fato de países como a Espanha, a Alemanha e a Itália já figurarem entre os principais destinos dos produtos exportados por essas empresas demonstra uma certa preocupação com a diversificação do mercado externo, bem como procura reduzir a dependência do mercado norte-americano.

Essa busca por novos mercados - em especial o europeu - mostra, na realidade, uma aceleração do processo iniciado em 2002. Nesse ano, as vendas para 
os Estados Unidos responderam por quase $84 \%$ do faturamento das indústrias calçadistas francanas no mercado externo. No ano seguinte, esse percentual caiu mais de ro pontos, para cerca de $72 \%$ das exportações e, no ano de 2004 , para cerca de $69 \%$. A tentativa de transferir parte dessas vendas para o mercado europeu fica clara na análise das vendas para a Espanha: em 2002, representaram 0,08\%; em 2003, subiram para $2,38 \%$; no ano de 2004 , foram para $3,27 \%$; e, em 2005 , apresentaram num patamar próximo a $7 \%$ de nossas exportações. Evolução semelhante ocorreu com as vendas para o Chile e a Bolívia, que saíram de percentuais próximos de $\mathrm{I} \%$ para patamares semelhantes aos da Espanha.

\section{CONCLUSÕES E RECOMENDAÇÕES}

Este estudo, de caráter exploratório, teve por objetivo investigar a internacionalização das indústrias de calçados da cidade de Franca, no Estado de São Paulo, buscando identificar as principais formas utilizadas e o estágio atual dessas empresas em seu processo de inserção no mercado internacional.

Os resultados da pesquisa realizada mostraram que as empresas da indústria calçadista francana seguem uma estratégia gradual de inserção no mercado internacional, em consonância com a literatura sobre o processo de internacionalização. Iniciam o processo com a exportação por intermédio de agentes (representantes de grandes distribuidoras internacionais) e, posteriormente, passam a exportar por conta própria. Em seguida, com o conhecimento adquirido nesses mercados, passam a instalar filiais comerciais ou representantes próprios em outros países. Finalmente, passam a produzir seus produtos em outros países, aproveitando-se de vantagens locacionais e de internalização.

A primeira premissa contida nas teorias da internacionalização parece se confirmar até o presente momento na indústria calçadista francana, embora de forma muito lenta: as empresas começam a exportar tarde e fazem sua inserção no mercado internacional de forma paulatina e seqüencial.

A exportação por intermédio de agentes, que são quase sempre representantes de grandes empresas distribuidoras internacionais (norte-americanas em sua maioria), permite a redução de uma eventual distância psicológica entre os dois países e a colocação dos Estados Unidos como o principal mercado para os calçados da indústria francana. A pesquisa mostrou ainda que os outros principais importadores dos calçados francanos são a Bolívia, o Chile e o Paraguai - países próximos tanto geográfica como psicologicamente, situados na América do Sul e de cultura latina como o Brasil.

As vendas para a Espanha cresceram nos últimos anos, talvez em razão das dificuldades encontradas pelos espanhóis de continuarem a produzir em seu 
país, devido aos elevados custos de produção na Europa, e também em razão da busca de alternativas de produção de sapatos finos, para distribuição naquele continente. A diversificação de mercados tem permitido às indústrias calçadistas da região diminuírem paulatinamente, nos últimos anos, a histórica dependência do mercado norte-americano, no qual elas estão perdendo competitividade em relação aos produtos produzidos por outros países, principalmente a China.

Quanto à segunda premissa das teorias da internacionalização pode-se dizer que o comportamento da indústria calçadista francana também apresenta consonância com a literatura pesquisada: as empresas procuram iniciar suas vendas externas para países mais próximos psicologicamente e, a partir da experiência adquirida, expandir-se para outros mais distantes.

Outra constatação é a de que a grande maioria das empresas se encontra, ainda, nos estágios iniciais do processo de internacionalização, ou seja, nas fases de exportação direta ou por intermédio de terceiros. As principais causas para o lento desenvolvimento dessas empresas no mercado internacional são a utilização de intermediários na comercialização; a concentração das vendas no mercado norte-americano; a não-utilização de marcas próprias; e o não-desenvolvimento de canais próprios de distribuição no exterior.

Essa forma de atuação faz com que as empresas não possuam um controle sobre suas vendas externas e dificulta o contato direto com os clientes no mercado internacional, resultando em uma posição de fragilidade perante os representantes das grandes companhias distribuidoras internacionais de calçados. Estes impõem aos fabricantes o modelo a ser produzido, o preço por unidade e a quantidade a ser comercializada. E, a cada elevação do dólar, na impossibilidade de as empresas cumprirem as condições estipuladas, esses representantes levam seus pedidos para outros países que as possam cumprir, como a China, na atualidade.

A alteração dessa realidade passa pela diversificação de mercados, pela adoção de novas formas de colocação do produto no mercado internacional, assim como pela utilização de marcas e canais próprios de distribuição, a exemplo do que estão fazendo algumas empresas citadas anteriormente.

No sentido de facilitar e acelerar tal processo, a intervenção de órgãos de apoio às exportações, o trabalho da universidade e o próprio desenvolvimento do arranjo produtivo local talvez sejam os caminhos mais adequados para mudar a realidade atual.

\section{REFERÊNCIAS}

AAKER, D. A.; KUMAR, V.; DAY, G. S. Pesquisa de marketing. São Paulo: Atlas, 200 I. ABICALÇADOS [Associação Brasileira das Indústrias Produtoras de Calçados]. Resenha estatística da indústria calçadista 2006. Disponível em: <http://www.abicalcados.com.br>. Acesso em: abr. 2006. 
ALMEIDA, F. C.; ROSA, S. T. A indústria de calçados e considerações sobre relações cooperativas em aglomerados industriais - observações sobre o aglomerado de Franca. FACEF Pesquisa, Franca, v. 7, n. I, p. 48-6I, 2004 .

ANDERSEN, O. On the internationalization process of firms: a critical analysis. Journal of International Business Studies, Washington, v. 24, n. 2, p. 209-23I, I993.

AULAK, P. S.; KOTABE, M.; TEEGEN, H. Export strategies and performance of firms from emerging economies: evidence from Brazil, Chile and Mexico. Academy of Management Journal, Greenvale, v. 43, n. 3, p. 342-36I, 2000.

AXINN, C. N. Export performance: do managerial perceptions make difference? International Marketing Review, London, v. 5, p. 6I-7I, Summer I988.

BARKEMA, H. G.; BELL, J. H. J.; PENNINGS, J. M. Foreign entry, cultural barriers, and learning. Strategic Management Journal, Chicago, v. I7, p. I5I-166, I996.

BARRETO, A. S. P. Internacionalização de empresas brasileiras: processos, pessoas e networks no investimento direto no exterior. I998. Tese (Doutorado)-Universidade Federal do Rio de Janeiro, Rio de Janeiro, I998.

BARRETTO, A. A internacionalização da firma sob o enfoque dos custos de transação. In: ROCHA, A. (Org.). A internacionalização das empresas brasileiras: estudos de gestão internacional. Rio de Janeiro: Mauad, 2002.

BILKEY, W. J.; TESAR, G. The export behavior of smaller-sized Wisconsin manufacturing firms. Journal of International Business Studies, Washington, v. 8, n. I, p. 93-98, I977.

CAMPANHOL, E. M.; SMITH, M. S. J. Empresa gestora de exportação para as pequenas empresas: alternativa para o incremento do desenvolvimento. In: COLLOQUE FRANCO BRÉSILIEN SUR LES DISTRICTS INDUSTRIELS. Grenoble: École Supèrieure des Affaires/Université Pierre-Mendès-France. Anais... Franca (SP): Facef, 2002.

CARVALHO, M.; ROCHA, A. Por que as empresas deixam de exportar: um olhar para a indústria brasileira de calçados. In: ROCHA, A. (Org.). A internacionalização das empresas brasileiras: estudos de gestão internacional. Rio de Janeiro: Mauad, 2002.

CARVALHO NETO, S. Competência para exportar: alternativa de crescimento para a indústria de calçados de Franca. 2004. Dissertação (Mestrado)-Faculdade de Ciências Econômicas, Administrativas e Contábeis de Franca, Franca, 2004.

CAVUSGIL, S. T. Differences among exporting firms based on their degree of internationalization. Journal of Business Research, Athens, v. I2, p. 195-208, I984a.

Organizational characteristics associated with export activity. Journal of Management Studies, Oxford, v. 2I, n. I, p. 3-22, I984b.

CHRISTENSEN, C. H.; ROCHA A.; GERTNER, R. K. An empirical investigation of the factors influencing exporting success of Brazilian firms. Journal of International Business Studies, Washington, v. I8, n. 3, p. 6I-78, I987.

CHURCHILl JÚNIOR, G. A.; PETER, J. P. Marketing: criando valor para o cliente. São Paulo: Saraiva, 2000.

CONSTANZI, R. N. Distribuição espacial da indústria de calçados no Brasil no século XX. I999. Dissertação (Mestrado)-Universidade de São Paulo, São Paulo, I999.

COSTA, A. B. O desempenho competitivo da produção de calçados do Brasil. In: COLLOQUE FRANCO BRÉSILIEN SUR LES DISTRICTS INDUSTRIELS, Grenoble: École Supèrieure des Affaires / Université Pierre-Mendès-France. Anais... Franca (SP): Facef, 2002. 
CZINKOTA, M.R.; JOHNSTON, W. J. Exporting: does sales volume make a difference? - Reply. Journal of International Business Studies, Washington, v. I6, p. I57-I6I, Summer I985.

DAL-SOTO, F. O processo de internacionalização de empresas brasileiras do setor de componentes para couro, calçados e artefatos. In: Workshop Internacionalização de empresas - Desafios e oportunidades para países emergentes, São Paulo, 2006.

DOMINGUINHOS, P. M. A internacionalização das empresas portuguesas: realidades e desafios. In: Paper 9ํㅡㄹ Encontro de Economia Industrial, Leiria (Portugal), jan. 200I.

DOURADO, C. A. Marketing na micro e pequena empresa fabricante de calçado masculino: o caso de Franca. 200I. Dissertação (Mestrado)-Faculdade de Ciências Econômicas, Administrativas e Contábeis de Franca, Franca, 200I.

DROUVOT et al. A posição dos calçados brasileiros de couro no mercado francês (I990-I999). In: COLLOQUE FRANCO BRÉSILIEN SUR LES DISTRICTS INDUSTRIELS, Grenoble: École Supèrieure des Affaires/Université Pierre-Mendès-France. Anais... Franca (SP): Facef, 2002.

DROUVOT, H.; MACHADO NETO, A. J. A indústria calçadista francesa diante do seu declínio. FACEF Pesquisa, Franca, v. 7, n. 3, p. 98-107, 2004.

DUNNING, J. H. The ecletic paradigm of international production: a restatement and some possible extensions. Journal of International Business Studies, Washington, v. I9, p. I-3I, I988.

FIGUEIREDO, K. F.; ALMEIDA, L. F. F. As barreiras à exportação de calçados brasileiros. In: ROCHA, A. (Org.). Gerência de exportação no Brasil. Rio de Janeiro: UFRJ, I988.

FUNDAÇÃO DOM CABRAL. Pesquisa sobre a internacionalização da empresa brasileira. Belo Horizonte, 2002.

GARCIA, R. Vantagens competitivas de empresas em aglomerações industriais: um estudo aplicado à indústria brasileira de calçados e sua inserção nas cadeias produtivas globais. 200ı. Tese (Doutorado)-Universidade Estadual de Campinas, Campinas, 200I.

Aglomerações setoriais ou distritos industriais: um estudo das indústrias têxtil e de calçados no Brasil. I996. Dissertação (Mestrado)-Universidade de Campinas Instituto de Economia, Campinas, 1996.

GIL, A. C. Como elaborar projetos de pesquisa. 3. ed. São Paulo: Atlas, I99I.

GONÇALVES, F. F. A influência da cultura organizacional no processo de internacionalização da empresa: caso Spoleto. 2008. Dissertação (Mestrado)-Universidade Federal do Rio de Janeiro, Rio de Janeiro, 2008.

HAIR JÚNIOR, J. F. et al. Análise multivariada de dados. 5. ed. Porto Alegre: Bookman, 2005.

HEMAIS, C. A.; HILAL, A. O processo de internacionalização da firma segundo a Escola Nórdica. In: ROCHA, A. (Org.). A internacionalização das empresas brasileiras: estudos de gestão internacional. Rio de Janeiro: Mauad, 2002.

HENRIQUES, L. F. R. A análise da competitividade da indústria calçadista do Vale dos Sinos: uma aplicação da metodologia de Michel Porter. I999. Dissertação (Mestrado)-Universidade Estadual de Campinas, Campinas, I999.

IGLÉSIAS, R. M.; VEIGA, P. M. Promoção das exportações via internacionalização de firmas de capital brasileiro. Brasília: Ministério da Fazenda, 200I.

JOHANSON, J.; WIEDERSHEIM-PAUL, F. The internationalization of firm: four swedish cases. Journal of Management Studies, Oxford, v. I2, n. 3, p. 305-322, October I975.

JOHANSON, J.; VAHLNE, J. E. The internationalization process of firm: a model of knowledge development and increasing foreign market commitments. Journal of International Business Studies, Washington, v. 8, n. I, p. 23-32, I977. 
JOHANSON, J.; VAHLNE, J. E. The mechanism of internationalization. International Marketing Review, Londres, v. 7, n. 4, p. II-24, I990.

Business relationship learning and commitment in the internationalization process. Journal of International Entrepreneurship, Amsterdan, v. I, p. 83-IоI, 2003.

. Commitment and opportunity development in the internationalization process: a note on the Uppsala Internationalization Process Model. Management International Review, Gutersloh, v. 42, n. 2, p. I65-I78, 2006.

KATSIKEAS, C. S. Export competitive advantages: the relevance of firm characteristics. International Marketing Review, London, v. II, n. 3, p. 33-53, I994.

KEDIA, B. L.; CHHOKAR, J. The impact of managerial attitudes on export behavior. American Journal of Small Business, New Jersey, p. 7-I7, Fall I985.

LEONIDOU, L. C.; KATSIKEAS, C. S. The export development process: an integrative review of empirical models. Journal of International Business Studies, Washington, n. 3, p. 517-55I, I996.

MACHADO NETO, A. J. Os determinantes do comportamento exportador da indústria calçadista francana. 2006. Tese (Doutorado)-Universidade de São Paulo, São Paulo, 2006.

MALHOTRA, N. Pesquisa de marketing: uma orientação aplicada. 3. ed. Porto Alegre: Bookman, 200 I. MATTAR, F. N. Pesquisa de marketing. São Paulo: Atlas, 1996.

MELIN, L. Internationalization as a strategy process. Strategic Management Journal, Chicago, v. I3, p. 99-II8, I992.

NEVES, M. F. et al. (Org.). Marketing \& exportação. São Paulo: Atlas, 200 I.

ORTEGA, S. M. S. La estratégia de internacionalización de la empresa: fatores determinantes del compromiso exportador em el sector vitivinícola español. I999. Tese (Doutorado)-Universidad de Las Palmas Gran Canaria (Espanha), I999.

PESTANA, M. H.; GAGEIRO, J. N. Análise de dados para as ciências sociais: a complementariedade do SPSS. Lisboa (Portugal): Sílabo, 2003.

PICCININI, V. L' industrie de la chaussure brésilienne face aux mutations internationales: stratégies et politique du personnel des entrerprises de la région de Vale dos Sinos. I990. Tese (Doutorado)École Supèrieure des Affaires, Université Pierre-Mendès-France, Grenoble (França), I990.

RABOCH, H.; AMAL, M. A internacionalização de pequenas empresas: um estudo de caso na região do vale do Itajaí. Dynamis Revista Tecno-Científica, Blumenau, v. I, n. I4, p. I-II, 2008.

REID S. D. The decision-maker and export entry and expansion. Journal of International Business Studies, Washington, v. I2, p. IoI-II2, Fall I98I.

REIS, C. N. A indústria brasileira de calçados: inserção internacional e dinâmica interna nos anos 80. I994. Tese (Doutorado)-Universidade Estadual de Campinas, Campinas, I994.

ROCHA, A.; CHRISTENSEN, C. H. Como as empresas brasileiras exportam: revisão dos estudos sobre exportação (I978-I990). In: ROCHA, A. (Org.). A internacionalização das empresas brasileiras: estudos de gestão internacional. Rio de Janeiro: Mauad, 2002.

SEBRAE [Serviço de Apoio às Micro e Pequenas Empresas]. Projeto APL Franca. Franca, 2004.

SERAGINI, L. Estágio do Brasil no comércio exterior e importância da marca, design e marketing para a competitividade dos produtos brasileiros. In: NEVES, M. F.; SCARE, R. F. (Org.). Marketing \& exportação. São Paulo: Atlas, 200I.

SINDIFRANCA [Sindicato da Indústria de Calçados de Franca]. A cadeia coureiro-calçadista. Franca: Natrontec, 2002.

Informações gerais sobre o setor calçadista. Franca: Sindifranca, mar. 2005. 
SMITH, M. S. J. A administração contábil nas micro e empresas de pequeno porte do setor calçadista de Franca. 2000. Dissertação (Mestrado)-Faculdade de Ciências Econômicas, Administrativas e Contábeis de Franca, Franca, 2000.

SOUZA, V. S. F.; DREHER, M. T.; AMAL, M. A influência da responsabilidade socioambiental no processo de internacionalização: o caso da Electro Aço Altona. Revista de Ciência da Administração, Florianópolis, v. 9, n. 19, p. 103-126, 2007.

SUZIGAN, W. et al. Sistemas produtivos locais no Estado de São Paulo: o caso da indústria de calçados de Franca. In: TIRONI, L. F. (Coord.). Industrialização descentralizada: sistemas industriais locais. Brasília: IPEA, 200I.

WELCH, D. E.; WELCH, L. S. The internationalization process and networks: a strategic management perspective. Journal of International Marketing, Chicago, v. 4, n. 3, p. II-28, I996.

WELCH, L. S.; LUOSTARINEN, R. Internationalization: evolution of a concept. Journal of General Management, Henley-on-Thames, v. I4, n. 2, p. 34-55, I988. 